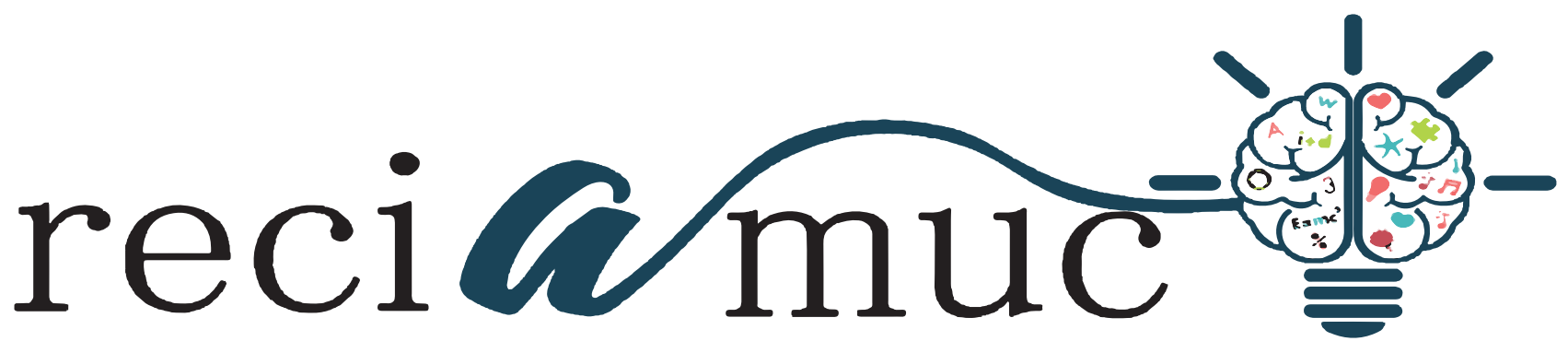

DOI: 10.26820/reciamuc/5.(1).ene.2021.170-179

URL: https://reciamuc.com/index.php/RECIAMUC/article/view/604

EDITORIAL: Saberes del Conocimiento

REVISTA: RECIAMUC

ISSN: 2588-0748

TIPO DE INVESTIGACIÓN: Artículo de revisión

CóDIGO UNESCO: 32 Ciencias Médicas

PAGINAS: $170-179$

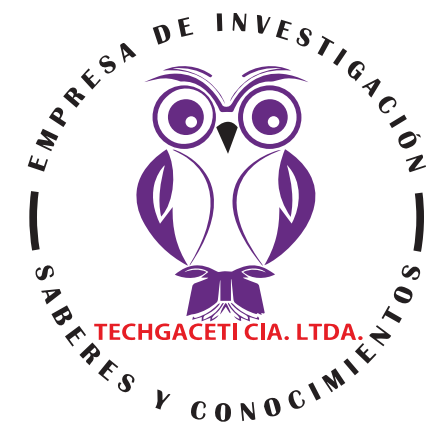

\title{
Epidemiologia y tratamiento de la conjuntivitis
}

Epidemiology and treatment of conjunctivitis

Síndrome de Marfan e suas conseqüências nos seres humanos

\section{Freddy Leonidas Monge Paladines'; Joe Luis Ordóñez Sánchez2; Joyce Vanessa Cando Herrera ${ }^{3}$}

RECIBIDO: 10/11/2020 ACEPTADO: 29/11/2020 PUBLICADO: 31/01/2021

1. Médico de la Universidad de Guayaquil; Investigador Independiente; Guayaquil, Ecuador; fmongepaladines_91@yahoo.com; (D) https://orcid.org/0000-0002-5574-642X

2. Especialista en Gestión de Servicios de Salud; Magister en Gerencia de Servicios de Salud; Diploma Superior en Gestión de Desarrollo de los Servicios de Salud; Doctor en Ciencias de la Salud; Obstetra; Universidad de Guayaquil; Guayaquil, Ecuador; joe.ordonezs@ug.edu.ec; (D) https://orcid.org/0000-00023316-818X

3. Médico de la Universidad Católica de Santiago de Guayaquil; Investigador Independiente; Guayaquil, Ecuador; vanessa94joyce@hotmail.com; (D) https://orcid.org/0000-0002-5656-1865

\section{CORRESPONDENCIA}

Freddy Leonidas Monge Paladines fmongepaladines_91@yahoo.com

\section{Guayaquil; Ecuador}

(C) RECIAMUC; Editorial Saberes del Conocimiento, 2021 


\section{RESUMEN}

La conjuntivitis viral es la causa general más común de conjuntivitis infecciosa y no requiere tratamiento; los signos y síntomas al momento de la presentación son variables. La conjuntivitis bacteriana es la segunda causa más común de conjuntivitis infecciosa, y la mayoría de los casos sin complicaciones se resuelven en 1 a 2 semanas. La importancia y adherencia de los párpados al despertar, la ausencia de prurito y la ausencia de antecedentes de conjuntivitis son los factores más fuertes asociados con la conjuntivitis bacteriana. Mediante el siguiente desarrollo investigativo, se pretende examinar el diagnóstico, el manejo y el tratamiento de la conjuntivitis, incluidos varios antibióticos y alternativas al uso de antibióticos en la conjuntivitis infecciosa y el uso de antihistamínicos y estabilizadores de mastocitos en la conjuntivitis alérgica. Los antibióticos tópicos disminuyen la duración de la conjuntivitis bacteriana y permiten un regreso más temprano a la escuela o al trabajo. La conjuntivitis secundaria a enfermedades de transmisión sexual como la clamidia y la gonorrea requiere un tratamiento sistémico además de la terapia con antibióticos tópicos. El prurito es el signo más constante de la conjuntivitis alérgica y el tratamiento consiste en antihistamínicos tópicos e inhibidores de mastocitos. La mayoría de los casos de conjuntivitis bacteriana son autolimitados y no es necesario tratamiento en casos no complicados. Sin embargo, la conjuntivitis causada por gonorrea o clamidia y la conjuntivitis en usuarios de lentes de contacto deben tratarse con antibióticos. El tratamiento de la conjuntivitis viral es de apoyo. El tratamiento con antihistamínicos y estabilizadores de mastocitos alivia los síntomas de la conjuntivitis alérgica.

Palabras clave: Conjuntivitis, Tratamiento, Riesgos.

\section{ABSTRACT}

Viral conjunctivitis is the most common general cause of infectious conjunctivitis and does not require treatment; signs and symptoms at presentation are variable. Bacterial conjunctivitis is the second most common cause of infectious conjunctivitis, and most uncomplicated cases resolve within 1 to 2 weeks. The importance and adherence of the eyelids upon awakening, the absence of itching, and the absence of a history of conjunctivitis are the strongest factors associated with bacterial conjunctivitis. Through the following research development, it is intended to examine the diagnosis, management and treatment of conjunctivitis, including various antibiotics and alternatives to the use of antibiotics in infectious conjunctivitis and the use of antihistamines and mast cell stabilizers in allergic conjunctivitis. Topical antibiotics decrease the duration of bacterial conjunctivitis and allow an earlier return to school or work. Conjunctivitis secondary to sexually transmitted diseases such as chlamydia and gonorrhea requires systemic treatment in addition to topical antibiotic therapy. Pruritus is the most consistent sign of allergic conjunctivitis, and treatment consists of topical antihistamines and mast cell inhibitors. Most cases of bacterial conjunctivitis are self-limited and treatment is not necessary in uncomplicated cases. However, conjunctivitis caused by gonorrhea or chlamydia and conjunctivitis in contact lens wearers should be treated with antibiotics. Treatment of viral conjunctivitis is supportive. Treatment with antihistamines and mast cell stabilizers alleviates the symptoms of allergic conjunctivitis.

KeyWords: Conjunctivitis, Treatment, Risks.

\section{RESUMO}

A conjuntivite viral é a causa geral mais comum de conjuntivite infecciosa e não requer tratamento; os sinais e sintomas na apresentação são variáveis. A conjuntivite bacteriana é a segunda causa mais comum de conjuntivite infecciosa, e a maioria dos casos não complicados são resolvidos no prazo de 1 a 2 semanas. A importância e aderência das pálpebras ao despertar, a ausência de prurido, e a ausência de história de conjuntivite são os factores mais fortes associados à conjuntivite bacteriana. Através do seguinte desenvolvimento de investigação, pretende-se examinar o diagnóstico, gestão e tratamento da conjuntivite, incluindo vários antibióticos e alternativas ao uso de antibióticos na conjuntivite infecciosa e o uso de anti-histamínicos e estabilizadores de mastócitos na conjuntivite alérgica. Os antibióticos tópicos diminuem a duração da conjuntivite bacteriana e permitem um regresso mais precoce à escola ou ao trabalho. A conjuntivite secundária a doenças sexualmente transmissíveis como a clamídia e a gonorreia requer um tratamento sistémico, para além da terapia antibiótica tópica. A prurido é o sinal mais consistente de conjuntivite alérgica, e o tratamento consiste em anti-histamínicos tópicos e inibidores de mastócitos. A maioria dos casos de conjuntivite bacteriana são auto-limitados e o tratamento não é necessário em casos não complicados. No entanto, a conjuntivite causada por gonorreia ou clamídia e conjuntivite em utilizadores de lentes de contacto deve ser tratada com antibióticos. O tratamento da conjuntivite viral é de apoio. $\mathrm{O}$ tratamento com anti-histamínicos e estabilizadores de mastócitos alivia os sintomas de conjuntivite alérgica.

Palavras-chave: Conjuntivite, Tratamento, Riscos. 


\section{Introducción}

La conjuntiva es una membrana delgada y translúcida que recubre la parte anterior de la esclerótica y el interior de los párpados. Tiene 2 partes, bulbar y palpebral. La porción bulbar comienza en el borde de la córnea y cubre la parte visible de la esclerótica; la parte palpebral recubre el interior de los párpados (Figura 1). La inflamación o infección de la conjuntiva "se conoce como conjuntivitis y se caracteriza por la dilatación de los vasos conjuntivales, lo que resulta en hiperemia y edema de la conjuntiva, típicamente con secreción asociada" (Leibowitz, 2000).

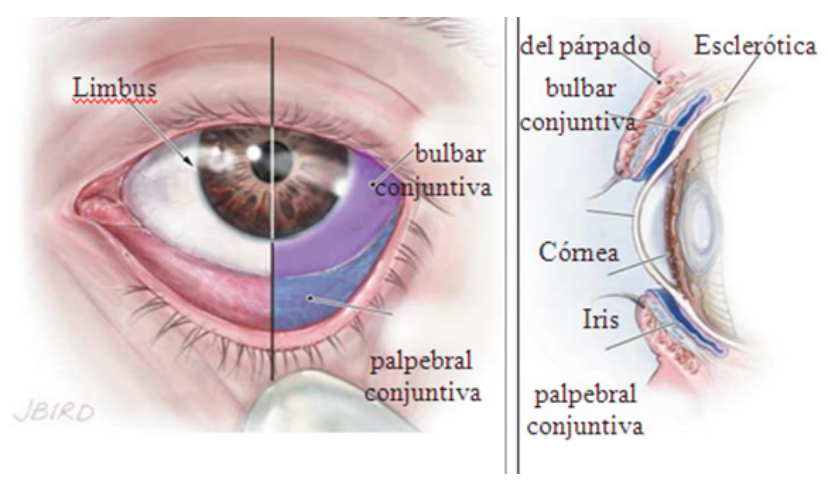

Figura 1. Anatomía conjuntival normal

Fuente: (Leibowitz, 2000)

La conjuntivitis afecta a muchas personas e impone cargas económicas y sociales a nivel mundial, ya que, representa una incidencia bastante considerada generando elevados costos en el tratamiento sobre todo de la conjuntivitis aguda. "Se estima que la conjuntivitis aguda afecta a 6 millones de personas anualmente en los Estados Unidos" (Smith \& Waycaster, 2009)

La mayoría de los pacientes con conjuntivitis son tratados inicialmente por médicos de atención primaria en lugar de profesionales de la vista. "Aproximadamente el 1\% de todas las visitas al consultorio de atención primaria están relacionadas con la conjuntivitis. En este sentido, el $70 \%$ de todos los pacientes con conjuntivitis aguda acuden a atención primaria y atención de urgencia"
(Kaufman, 2011)

La prevalencia de conjuntivitis varía según la causa subyacente, que puede estar influenciada por la edad del paciente, así como por la época del año. La conjuntivitis viral es la causa más común de conjuntivitis infecciosa tanto en general como en la población adulta y es más prevalente en verano.

La conjuntivitis bacteriana es la segunda causa más común y es responsable de la mayoría (50\% -75\%) de los casos en niños de14, se observa con mayor frecuencia de diciembre a abril. La conjuntivitis alérgica es la causa más frecuente, que afecta a $15 \%$ a $40 \%$ de la población, y se observa con más frecuencia en primavera y verano (Hoding, 2008).

La conjuntivitis se puede dividir en causas infecciosas y no infecciosas. Los virus y las bacterias son las causas infecciosas más comunes. "La conjuntivitis no infecciosa incluye conjuntivitis alérgica, tóxica y cicatricial, así como inflamación secundaria a enfermedades inmuno mediadas y procesos neoplásicos" (Brien, Jeng, McDonald, \& Raizman, 2009). La enfermedad también puede ser clasificada en aguda, hiperaguda y crónica de acuerdo con el modo de aparición y la gravedad de la respuesta clínica. Además, puede ser primaria o secundaria a enfermedades sistémicas como gonorrea, clamidia, enfermedad de injerto contra huésped y síndrome de Reiter, en cuyo caso se justifica el tratamiento sistémico.

Es importante diferenciar la conjuntivitis de otras enfermedades oculares que amenazan la vista y que tienen una presentación clínica similar y tomar las decisiones adecuadas sobre pruebas, tratamientos 0 derivaciones adicionales. Un enfoque algorítmico que utiliza una historia ocular enfocada junto con un examen ocular con lápiz óptico puede ser útil para el diagnóstico y el tratamiento. Debido a que la conjuntivitis y muchas otras enfermedades oculares 
pueden presentarse como "ojos rojos", el diagnóstico diferencial de los ojos rojos y el conocimiento de las características típicas de cada enfermedad en esta categoría son importantes.

En tal sentido, y en relación a la epidemiologia e incidencia de este tipo de afección, es necesario evaluar las características clínicas para diferenciar el tipo de conjuntivitis y brindar un tratamiento adecuado. Por lo cual y durante el desarrollo del siguiente proceso investigativo se pretende dar a conocer los posibles tratamientos en aras de ofrecer a futuras investigaciones información de interés.

\section{Metodología}

Para el desarrollo de este proceso investigativo, se plantea como metodología la encaminada hacia una orientación científica particular que se encuentra determinada por la necesidad de indagar en forma precisa y coherente una situación, en tal sentido Davila, (2015) define la metodología "como aquellos pasos anteriores que son seleccionados por el investigador para lograr resultados favorables que le ayuden a plantear nuevas ideas" (p.66)

Lo citado por el autor, lleva a entender que el desarrollo de la acción investigativa busca simplemente coordinar acciones enmarcadas en una revisión bibliográfica con el fin de complementar ideas previas relacionadas Epidemiologia y tratamiento de la conjuntivitis a través de una revisión de literatura, para así finalmente elaborar un cuerpo de consideraciones generales que ayuden a ampliar el interés propuesto.

\section{Tipo de Investigación}

Dentro de toda práctica investigativa, se precisan acciones de carácter metodológico mediante las cuales se logra conocer y proyectar los eventos posibles que la determinan. En este sentido, la presente investigación corresponde al tipo documental, definido por Castro (2016), "se ocupa del estudio de problemas planteados a nivel teórico, la información requerida para abordarlos se encuentra básicamente en materiales impresos, audiovisuales y / o electrónicos". (p.41).

En consideración a esta definición, la orientación metodológica incluye la oportunidad de cumplir con una serie de actividades inherentes a la revisión y lectura de diversos documentos, donde se encuentran ideas explicitas relacionadas con los tópicos encargados de identificar una característica inmersa en el estudio. Por lo tanto, se realizaron continuas interpretaciones con el claro propósito de revisar aquellas apreciaciones propuestas por diferentes investigadores en relación al tema de interés, para luego dar la respectiva argumentación a los planteamientos, en función a las necesidades encontradas en la investigación, apoyados en las herramientas tecnológicas para la búsqueda de trabajos con valor científico disponibles en la web que tenían conexión con el objetivo principal de la investigación.

\section{Fuentes Documentales}

El análisis correspondiente a las características que predomina en el tema seleccionado, llevan a incluir diferentes fuentes documentales encargadas de darle el respectivo valor científico y en ese sentido cumplir con la valoración de los hechos a fin de generar nuevos criterios que sirven de referencia a otros procesos investigativos. Para Castro,(2016) las fuentes documentales incorporadas en la investigación documental o bibliográfica, "representa la suma de materiales sistemáticos que son revisados en forma rigurosa y profunda para llegar a un análisis del fenómeno" (p.41). Por lo tanto, se procedió a cumplir con la lectura previa determinada para encontrar aquellos aspectos estrechamente vinculados con el tema, con el fin de explicar mediante un desarrollo las respectivas apreciaciones generales de importancia. 
Técnicas para la Recolección de la Información

La conducción de la investigación para ser realizada en función a las particularidades que determinan a los estudios documentales, tiene como fin el desarrollo de un conjunto de acciones encargadas de llevar a la selección de técnicas estrechamente vinculadas con las características del estudio. Bolívar, (2015), refiere, que es "una técnica particular para aportar ayuda a los procedimientos de selección de las ideas primarias y secundarias". (p.71).

Tal como lo expresa, Bolívar, (2015) "Las técnicas documentales proporcionan las herramientas esenciales y determinantes para responder a los objetivos formulados y llegar a resultados efectivos" (p. 58). Es decir, para responder con eficiencia a las necesidades investigativas, se introdujeron como técnica de recolección el método inductivo, que hizo posible llevar a cabo una valoración de los hechos de forma particular para llegar a la explicación desde una visión general. El autor Bolívar, (2015) tambien expresa que las técnicas de procesamiento de datos en los estudios documentales "son las encargadas de ofrecer al investigador la visión o pasos que deben cumplir durante su ejercicio, cada una de ellas debe estar en correspondencia con el nivel a emplear" (p. 123). Esto indica, que para llevar a cabo el procesamiento de los datos obtenidos una vez aplicadas las técnicas seleccionadas, tales como: fichas de resumen, textual, registros descriptivos entre otros, los mismos se deben ajustar al nivel que ha sido seleccionado.

\section{Resultados}

\section{Cómo diferenciar la conjuntivitis según sus orígenes}

Historia y examen físico

El examen y la historia ocular enfocados son cruciales para tomar decisiones adecuadas sobre el tratamiento y el manejo de cualquier afección ocular, incluida la conjuntivitis. El tipo de secreción ocular y los síntomas oculares se pueden utilizar para determinar la causa de la conjuntivitis.

Por ejemplo, una descarga purulenta o mucopurulenta a menudo se debe a una conjuntivitis bacteriana (Figura 2A y Figura 2B), mientras que una descarga acuosa es más característica de la conjuntivitis viral (Figura 2C); la picazón también se asocia con conjuntivitis alérgica (Brien, Jeng, McDonald, \& Raizman, 2009).

Sin embargo, la presentación clínica generalmente es inespecífica. Confiar en el tipo de alta y los síntomas del paciente no siempre conduce a un diagnóstico preciso. Esto se debe a que se carece de evidencia científica que correlación de los signos y síntomas de la conjuntivitis con la causa subyacente. Por ejemplo, "en un estudio de pacientes con conjuntivitis bacteriana con cultivo positivo, el 58\% tenía prurito, el 65\% tenía ardor y el 35\% tenía secreción serosa o nula, lo que ilustra la inespecificidad de los signos y síntomas de esta enfermedad" (Riet, Bindels, Sloos, \& Weert, 2004).

En 2003, un gran metanálisis no logró encontrar ningún estudio clínico que correlacionara los signos y síntomas de la conjuntivitis con la causa subyacente; más tarde, los mismos autores Riet, Bindels, Sloos, \& Weert, (2004) "realizaron un estudio prospectivo y encontraron que una combinación de 3 signos (peso bilateral de los párpados, ausencia de picazón y ausencia de antecedentes de conjuntivitis) predecía fuertemente la conjuntivitis bacteriana". Los autores Tarabishy \& Jeng, (2008) afirman:

Tener ambos párpados adheridos por la mañana fue un predictor más fuerte de un resultado positivo de cultivo bacteriano, y la picazón o un episodio previo de conjuntivitis hizo que un resultado positivo del cultivo bacteriano fuera menos probable. Además, el tipo de secreción (purulenta, mucosa o acuosa) u otros síntomas no eran específicos de ninguna clase particular de conjun- 
tivitis (p. 507).

Aunque en el ámbito de la atención primaria un examen ocular a menudo es limitado debido a la falta de una lámpara de hendidura, se puede obtener información útil con una simple linterna. El examen ocular debe centrarse en la evaluación de la agudeza visual, el tipo de secreción, la opacidad corneal, la forma y el tamaño de la pupila, la hinchazón del párpado y la presencia de proptosis.

\section{Investigaciones de laboratorio}

De acuerdo con Espinosa, (2004) "la obtención de cultivos conjuntivales generalmente se reserva para casos de sospecha de conjuntivitis neonatal infecciosa, conjuntivitis recurrente, conjuntivitis recalcitrante a la terapia, conjuntivitis que se presenta con secreción purulenta grave y casos sospechosos de infección gonocócica o clamidial". La prueba rápida de antígenos en el consultorio está disponible para los adenovirus y tiene una sensibilidad del $89 \%$ y una especificidad de hasta el 94\%. "Esta prueba puede identificar las causas virales de la conjuntivitis y prevenir el uso innecesario de antibióticos" (Alonso \& Bartolomé, 2005).

\section{Conjuntivitis infecciosa.}

\section{Conjuntivitis Viral}

\section{Epidemiología, causa y presentación}

Los virus causan hasta el $80 \%$ de todos los casos de conjuntivitis aguda. "La tasa de precisión clínica en el diagnóstico de conjuntivitis viral es inferior al 50\% en comparación con la confirmación de laboratorio. Muchos casos se diagnostican erróneamente como conjuntivitis bacteriana" (Brien, Jeng, McDonald, \& Raizman, 2009)

En este sentido Kaufman, (2011) expresa que "entre el 65 y el $90 \%$ de los casos de conjuntivitis viral son causados por adenovirus, y producen 2 de las entidades clínicas comunes asociadas con conjuntivitis viral, fiebre faringoconjuntival y queratoconjuntivitis epidémica".
La fiebre faringoconjuntival se caracteriza por la aparición súbita de fiebre alta, faringitis y conjuntivitis bilateral y por agrandamiento de los ganglios linfáticos peri auriculares, mientras que la queratoconjuntivitis epidémica es más grave y se presenta con secreción acuosa, hiperemia, quemosis y linfadenopatía ipsilateral. Se observa linfadenopatía hasta en un 50\% de los casos de conjuntivitis viral y es más frecuente en la conjuntivitis viral en comparación con la conjuntivitis bacteriana (Kaufman, 2011)

\section{Prevención y tratamiento}

La conjuntivitis viral secundaria a adenovirus es muy contagiosa y se ha estimado que el riesgo de transmisión es del 10\% al $50 \%$. El virus se transmite por contacto directo a través de dedos contaminados, instrumentos médicos, agua de piscina o artículos personales. Debido a las altas tasas de transmisión, "se ha recomendado el lavado de manos, la desinfección estricta de los instrumentos y el aislamiento de los pacientes infectados del resto de la clínica" (Mayo Clinic, 2020). Se estima que la incubación y la transmisibilidad son de 5 a 12 días y de 10 a 14 días, respectivamente.

Aunque no existe un tratamiento eficaz, "las lágrimas artificiales, los antihistamínicos tópicos o las compresas frías pueden ser útiles para aliviar algunos de los síntomas. Los medicamentos antivirales disponibles no son útiles y los antibióticos tópicos no están indicados (Mayo Clinic, 2020). Los antibióticos tópicos no protegen frente a infecciones secundarias y su uso puede complicar la presentación clínica provocando alergia y toxicidad, lo que lleva a retrasar el diagnóstico de otras posibles enfermedades oculares.

El uso de gotas para los ojos con antibióticos puede aumentar el riesgo de propagar la infección al otro ojo debido a goteros contaminados. El aumento de la resistencia también es motivo de preocupación con el uso frecuente de antibióticos. Los pacientes deben ser remitidos a un oftalmólogo si los

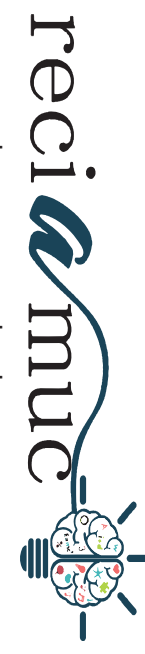


síntomas no desaparecen después de 7 a 10 días debido al riesgo de complicaciones.

\section{Conjuntivitis por herpes}

El virus del herpes simple "comprende del $1,3 \%$ al $4,8 \%$ de todos los casos de conjuntivitis aguda; la conjuntivitis causada por el virus suele ser unilateral, la secreción es fina y acuosa, y puede haber lesiones vesiculares palpebrales acompañantes" (Brien, Jeng, McDonald, \& Raizman, 2009). En este sentido, Azar, Dhaliwal, \& Bower, (2006) "recomiendan antivirales tópicos y orales para acortar el curso de la enfermedad. Deben evitarse los corticosteroides tópicos porque potencian el virus y pueden causar daño"

El virus del herpes zóster, responsable de la culebrilla, puede afectar al tejido ocular, especialmente si están afectadas la primera y la segunda ramas del nervio trigémino. "Los párpados representan un (45,8\%) son el sitio más común de afectación ocular, seguido de la conjuntiva $(41,1 \%)$. La complicación corneal y la uveítis pueden estar presentes en el $38,2 \%$ y el $19,1 \%$ de los casos, respectivamente" (Shrestha \& Shah, 2011). Los pacientes con sospecha de afectación palpebral u ocular o aquellos que presenten el signo de Hutchinson (vesículas en la punta de la nariz, que tienen una alta correlación con la afectación corneal) deben ser remitidos para una evaluación oftálmica exhaustiva. El tratamiento suele consistir en una combinación de antivirales orales y esteroides tópicos.

\section{Conjuntivitis bacteriana}

\section{Epidemiología, causa y presentación}

La conjuntivitis bacteriana puede contraerse directamente de individuos infectados o puede resultar de la proliferación anormal de la flora conjuntival nativa. Los dedos contaminados, la diseminación oculogenital y los fómites contaminados son vías de transmisión comunes. Además, "ciertas afecciones, como la producción de lágrimas comprometida, la alteración de la barrera epitelial natural, la anomalía de las estructuras anexiales, el trauma y el estado inmunodeprimido predisponen a la conjuntivitis bacteriana" (Epling, 2010).

Los patógenos más comunes para la conjuntivitis bacteriana en adultos son las especies de estafilococos, seguidas de Streptococcus pneumoniae y Haemophilus influenzae. "En los niños, la enfermedad suele ser causada por $\mathrm{H}$. influenzae, S. pneumonia y Moraxella catarrhalis. El curso de la enfermedad suele durar de 7 a 10 días" (Figura 2) (Brien, Jeng, McDonald, \& Raizman, 2009).
A Bacteriana
B Hiperaguda
C Conjuntivitis viral

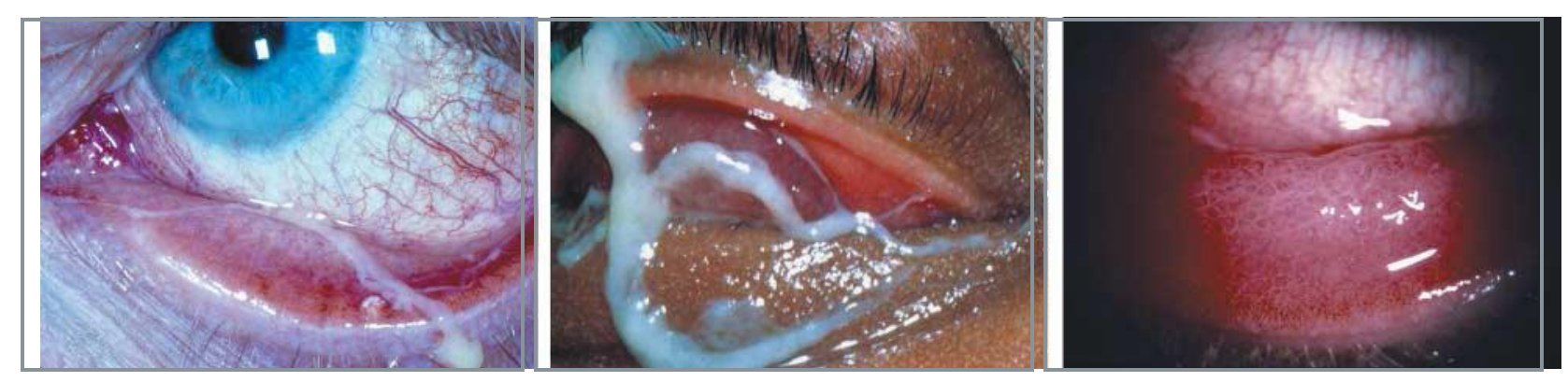

Figura 2. Aspecto característico de la conjuntivitis bacteriana y viral

Fuente: (Brien, Jeng, McDonald, \& Raizman, 2009) 
En la figura $\mathrm{N}^{\circ} 2$ se puede observar, $\mathrm{A}$, Conjuntivitis bacteriana caracterizada por secreción mucopurulenta e hiperemia conjuntival. B, Secreción purulenta grave observada en conjuntivitis bacteriana hiperaguda secundaria a gonorrea. C. Respuesta intensamente hiperémica con descarga acuosa característica de conjuntivitis viral.

La conjuntivitis bacteriana hiperaguda se presenta con una secreción purulenta copiosa intensa y disminución de la visión (Figura 2B). Por lo general, se acompaña de hinchazón palpebral, dolor ocular a la palpación y adenopatía preauricular.

Es causada por Neisseria gonorrhoeae y conlleva un alto riesgo de afectación de la córnea y posterior perforación de la córnea. El tratamiento de la conjuntivitis hiperaguda secundaria a N. gonorrhoeae consiste en ceftriaxona intramuscular, y la infección por clamidia concurrente debe tratarse en consecuencia. (Brien, Jeng, McDonald, \& Raizman, 2009)

La conjuntivitis bacteriana crónica se usa para describir cualquier conjuntivitis que dure más de 4 semanas, "siendo Staphylococcus aureus, Moraxella lacunata, bacterias andentéricas las causas más frecuentes en este entorno" (Espinosa, 2004); Se debe buscar una consulta oftalmológica para su manejo.

Los signos y síntomas incluyen ojos rojos, secreción purulenta o mucopurulenta y quemosis (Figura 2A).

Se estima que el período de incubación y transmisibilidad es de 1 a 7 días y de 2 a 7 días, respectivamente. Importancia bilateral de los párpados y adherencia de los párpados, la falta de picazón y la ausencia de antecedentes de conjuntivitis son fuertes predictores positivos de conjuntivitis bacteriana (Tarabishy \& Jeng, 2008)

Siempre se debe cultivar una secreción purulenta severa y se debe considerar la conjuntivitis gonocócica (Figura 2B). La conjuntivitis no responde al tratamiento antibiótico estándar en el sexo Los pacientes activos justifican una evaluación por clamidia. "La posibilidad de queratitis bacteriana es alta en los usuarios de lentes de contacto, que deben ser tratados con antibióticos tópicos y remitidos a un oftalmólogo" (Hoding, 2008). A los pacientes que usan lentes de contacto se le debe pedir que suspenda su uso de inmediato.

\section{Uso de antibióticos en la conjuntivitis bacteriana}

Al menos el $60 \%$ de los casos de conjuntivitis bacteriana aguda sospechada o demostrada por cultivo son autolimitantes dentro de 1 a 2 semanas de la presentación. Los antibióticos reducen la duración de la enfermedad, no se han observado diferencias en los resultados entre los grupos de tratamiento y placebo.

En un gran metaanálisis que consistió en una revisión de 3673 pacientes en 11 ensayos clínicos aleatorizados, hubo un aumento de aproximadamente un $10 \%$ en la tasa de mejoría clínica en comparación con el placebo para los pacientes que recibieron 2 a 5 días o 6 a 10 días de tratamiento con antibióticos en comparación con el placebo. No se informaron resultados graves que amenazaran la vista en ninguno de los grupos de placebo (Sheikh \& Hurwitz, 2005).

Algunas bacterias altamente virulentas, como S. pneumoniae, N. gonorrhoeae y $H$. influenzae, pueden penetrar una defensa intacta del huésped con más facilidad y causar daños más graves.

Los antibióticos tópicos parecen ser más eficaces en pacientes que tienen cultivos bacterianos positivos. En una amplia revisión sistémica, se encontró que eran eficaces para "aumentar la tasa de curación clínica y microbiológica en el grupo de pacientes con conjuntivitis bacteriana demostrada por cultivo, mientras que solo se observó una mejor tasa de curación microbiana en el grupo de pacientes con sospecha clíni-

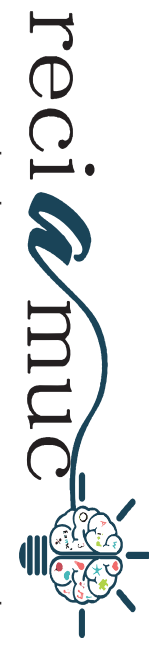


ca conjuntivitis bacteriana" (Epling, 2010). Otros estudios no encontraron diferencias significativas en la tasa de curación clínica cuando las frecuencias de los antibióticos administrados se modificaron ligeramente.

\section{Opciones de antibióticos}

Todas las gotas para los ojos con antibióticos de amplio espectro parecen, en general, ser eficaces para tratar la conjuntivitis bacteriana. No existen diferencias significativas para lograr la curación clínica entre cualquiera de los antibióticos tópicos de amplio espectro. Los factores que influyen en la elección de antibióticos son la disponibilidad local, las alergias del paciente, los patrones de resistencia y el costo.

Alternativas a la terapia antibiótica inmediata: Hasta donde se sabe, no se han realizado estudios para evaluar la eficacia de descongestionantes oculares, solución salina tópica o compresas calientes para el tratamiento de la conjuntivitis bacteriana. Esteroides tópicos debe evitarse debido al riesgo de prolongar potencialmente el curso de la enfermedad y potenciar la infección.

\section{Conclusiones}

Durante el desarrollo del proceso investigativo se observó, que la conjuntivitis viral no herpética seguida de conjuntivitis bacteriana es la causa más común de conjuntivitis infecciosa. La conjuntivitis alérgica afecta en alguna ocasión a gran parte de la población, pero solo una pequeña proporción busca atención médica. La mayoría de los casos de conjuntivitis viral se deben a adenovirus.

También se observó, que el uso de antibióticos tópicos contra la conjuntivitis no viral no tiene ninguna función, y deben evitarse debido a los efectos adversos del tratamiento. Usar una prueba rápida de antígenos para diagnosticar la conjuntivitis viral y evitar el uso inadecuado de antibióticos es una estrategia adecuada. Los cultivos son útiles en los casos que no responden al trata- miento, casos de conjuntivitis hiperaguda y sospecha de conjuntivitis por clamidia. Sin embargo, el tratamiento con antibióticos tópicos generalmente se recomienda para pacientes que usan lentes, aquellos con secreción mucopurulenta y dolor ocular, casos sospechosos de conjuntivitis por clamidia, gonocócica y pacientes con enfermedad preexistente de la superficie ocular.

Las ventajas del uso de antibióticos incluyen la resolución temprana de la enfermedad, regreso temprano a las actividades cotidianas (trabajo, escuela), y la posibilidad de una disminución de las complicaciones de la conjuntivitis. La mayoría de los casos de conjuntivitis alérgica se deben a alergias estacionales. Los antihistamínicos, los inhibidores de mastocitos y los esteroides tópicos (en casos seleccionados) están indicados para el tratamiento de la conjuntivitis alérgica, deben usarse con prudencia y solo después de que se haya realizado un examen oftalmológico completo para descartar una infección herpética o compromiso de la córnea, los cuales pueden empeorar con los esteroides.

Finalmente se puede concluir, que los beneficios del tratamiento con antibióticos incluyen una disminución de la transmisibilidad. Al mismo tiempo, los efectos adversos están ausentes si no se utilizan antibióticos en casos no complicados de conjuntivitis bacteriana. Por lo tanto, ningún tratamiento, una política de esperar y el tratamiento adecuado e inmediato parecen ser enfoques razonables en casos de conjuntivitis no complicada. Adicionalmente, los médicos deben estar atentos para no pasar por alto las condiciones que amenazan la vista por similitudes con la conjuntivitis.

\section{Bibliografía}

Alonso, C., \& Bartolomé, R. (2005). Procedimientos en Microbiología Clínica. Recomendaciones de la Sociedad Española de Enfermedades Infecciosas y Microbiología Clínica, Madrid.

Azar, M., Dhaliwal, D., \& Bower, K. (2006). Possible 
consequences of shaking hands with your patients with epidemic keratoconjunctivitis. Am J Ophthalmol , 711-712.

Brien, T., Jeng, B., McDonald, M., \& Raizman, M. (2009). Acute conjunctivitis: truth and misconceptions. Curr Med Res Opin , 1953-1961.

Epling, J. (2010). Bacterial conjunctivitis. Clin Evid.

Espinosa, E. (2004). Sintomatología, tratamiento y medidas preventivas. Mosby, Vol. 23. (Núm. 11.), 60-66.

Hoding, G. (2008). Acute bacterial conjunctivitis. Acta Ophthalmol , 5-17.

Kaufman, H. (2011). Adenovirus advances: new diagnostic and therapeutic options. Curr Opin Ophthalmol , 290-293.

Leibowitz, H. (2000). The red eye. N Engl J Med, 345-351.
Mayo Clinic. (2020, Febrero 13). Mayo Clinic Org. Retrieved Diciembre 16, 2020 from https://www. mayoclinic.org/es-es/diseases-conditions/pinkeye/symptoms-causes/syc-20376355

Riet, G., Bindels, P., Sloos, J., \& Weert, H. (2004). Predicting bacterial cause in infectious conjunctivitis. BMJ , 206-210.

Sheikh, A., \& Hurwitz, B. (2005). Topical antibiotics for acute bacterial conjunctivitis. Br J Gen Pract , 962-964.

Shrestha, G., \& Shah, D. (2011). Ocular manifestations in herpes zoster ophthalmicus. Nepal J Ophthalmol, 165-171.

Smith, A., \& Waycaster, C. (2009). Estimate of the direct and indirect annual cost of bacterial conjunctivitis in the United States. BMC Ophthalmol , 3.

Tarabishy, A., \& Jeng, B. (2008). Bacterial conjunctivitis: a review for internists. Cleve Clin J Med, 507512.

CITAR ESTE ARTICULO:

Monge Paladines, F. L., Ordóñez Sánchez, J. L., \& Cando Herrera, J. V. (2021).

Epidemiologia y tratamiento de la conjuntivitis. RECIAMUC, 5(1), 170-179. https://doi.org/10.26820//reciamuc/5.(1).ene.2021.170-179 